\section{Dementia

\title{
Adequacy of Using Consensus Guidelines for Diagnosis of Dementia with Lewy Bodies in Clinical Trials for Drug Development
}

\author{
Manabu Ikeda ${ }^{a}$ Etsuro Mori ${ }^{b}$ Eizo Isekic Sadao Katayama ${ }^{\mathrm{e}}$ \\ Yasuto Higashi $^{\text {f }}$ Mamoru Hashimoto $^{a}$ Hideaki Miyagishid $^{d}$ \\ Masaki Nakagawad Kenji Kosakag \\ ${ }^{a}$ Department of Neuropsychiatry, Faculty of Life Sciences, Kumamoto University, \\ Kumamoto, bepartment of Behavioral Neurology and Cognitive Neuroscience, Tohoku \\ University Graduate School of Medicine, Sendai, 'Juntendo Tokyo Koto Geriatric Medical \\ Center, and ${ }^{d}$ Eisai Product Creation Systems, Eisai Co., Ltd., Tokyo, ${ }^{e}$ Katayama Medical Clinic, \\ Kurashiki, ${ }^{\mathrm{f}}$ Department of Neurology, Himeji Central Hospital, Himeji, and g Department of \\ Psychiatry, Yokohama City University School of Medicine, Yokohama, Japan
}

\section{Key Words}

Dementia - Lewy bodies - Clinical characteristics - Diagnosis - Randomised controlled trials .

Psychiatry · Neurology

\begin{abstract}
Background/Aims: To evaluate the adequacy of using the consensus diagnostic criteria for dementia with Lewy bodies (DLB) to recruit patients with homogeneous characteristics in future clinical trials, where multiple departments of multinational centres are expected to participate with a long enrolment period, and additionally, to contribute to the possible future criteria revision. Methods: Using data from 2 trials of donepezil for DLB, conducted 3 years apart, characteristics in patients with probable DLB were analysed and compared between studies and between psychiatric and neurological centres. Results: In 273 patients (phase II: 135, phase III: 138; psychiatric: 73, neurological: 184), clinical characteristics overall were very similar between studies, and between specialty centres, excluding distinctive parkinsonism in the neurological versus psychiatric centres: incidence of parkinsonism (91.8 vs. $71.2 \%, p<$ 0.001 ), Hoehn and Yahr stage (III: 55.0 vs. $21.2 \%, p<0.001$ ), and concomitant anti-Parkinson medication ( 24.5 vs. $11.0 \%, p=0.017$ ). Rapid eye movement sleep behaviour disorder, depression, and delusion, suggestive or supportive features, were observed in 35-40\%. Additionally, a high prevalence (55.3\%) of anxiety was observed. Conclusion: Employing the consensus criteria is adequate to enrol homogeneous DLB patients into future clinical trials regardless of the specialty of centres and time. Further discussion could involve adding anxiety to future criteria.


Ikeda et al.: Adequacy of Using Consensus Guidelines for Diagnosis of Dementia with Lewy Bodies in Clinical Trials for Drug Development

\section{Introduction}

Dementia with Lewy bodies (DLB) is a common type of dementia among the elderly and accounts for the second largest group of patients with dementia, following Alzheimer's disease (AD) [1]. DLB includes the core clinical features of neuropsychiatric symptoms and motor symptoms of parkinsonism as well as cognitive impairment characterised by deficits of attention, executive function, and visual perception.

The currently accepted diagnostic criteria for DLB were published in 1996 by the Consortium on DLB [2] and revised in 2005 [3]. All core features and some of the suggestive features defined in the revised criteria were adopted in the recently published diagnostic criteria for neurocognitive disorders with Lewy bodies in the Fifth Edition of the Diagnostic and Statistical Manual of Mental Disorders (DSM-5) [4]. Several studies reported that these consensus criteria offer high specificity but relatively low sensitivity [5-7]. Therefore, further refinement of the criteria is indicated $[8,9]$. Therapeutic research, including research on nonpharmacological approaches, as well as clinical research require both high specificity and sensitivity in diagnostic criteria, although disease-modifying drug trials and etiological research require as homogeneous a disease as possible.

The pharmacological management of DLB can be one of the most challenging issues that neurologists, psychiatrists, geriatricians, and primary care physicians face [10]. However, only a few randomised placebo-controlled trials (RCTs) targeting DLB have been conducted, and no drug has been approved in any country except Japan, where only donepezil is available for DLB. Moreover, it is difficult to enrol a large number of patients into clinical trials for DLB, especially RCTs, owing to its wide variety of treatment targets and high caregiver burden [11]. Therefore, future RCTs in DLB will inevitably recruit patients from various specialty departments (e.g. neurology, psychiatry, geriatrics) of a large number of multinational centres and have a long enrolment period. However, there is little information about whether DLB patients with homogeneous characteristics can be enrolled in such trials using the current consensus diagnostic criteria.

We have previously conducted 3 clinical trials [12-16] on donepezil for DLB including 2 RCTs $[12,14]$ that enrolled a total of 281 patients diagnosed with probable DLB according to the original consensus criteria [2]. These studies were conducted 3 years apart. In this paper, data on clinical characteristics of these patients were further analysed to examine the adequacy of using currently accepted diagnostic criteria in future studies. We also investigated the prevalence of suggestive and supportive features defined in the revised criteria [3] in these patients to contribute to the possible future revision of the diagnostic criteria.

\section{Methods}

Data Utilised for the Analysis

Data for the present analysis were collected from 1 phase II and 1 phase III study of donepezil in patients with DLB conducted in Japan. A 12-week, phase II, exploratory RCT was conducted to investigate the efficacy and safety of donepezil at 3,5, and $10 \mathrm{mg}$ /day from October 2007 (clinicaltrials.gov reference: NCT00543855). Subsequently, a confirmatory phase III trial including a 16-week RCT phase was conducted from February 2011 to confirm the superiority of donepezil at 5 and $10 \mathrm{mg} /$ day for 12 weeks over placebo (clinicaltrials. gov reference: NCT01278407). Each study was conducted in accordance with the principles of the Declaration of Helsinki. The protocols were approved by the institutional review board at each participating centre. The results of the studies have previously been reported [12-16].

Patients

Patients were recruited according to nearly identical criteria in both studies. Patients diagnosed with probable DLB in accordance with the original consensus criteria [2] were recruited mainly from psychi- 
Ikeda et al.: Adequacy of Using Consensus Guidelines for Diagnosis of Dementia with Lewy Bodies in Clinical Trials for Drug Development

atric or neurological specialty centres throughout Japan (48 and 72 centres in phase II and III, respectively).

Eligible patients were outpatients aged $\geq 50$ years with mild to moderate-severe dementia [a score of $10-26$ on the Mini-Mental State Examination (MMSE) and Clinical Dementia Rating (CDR) $\geq 0.5$ ] and behavioural and psychiatric symptoms (BPSD) [Neuropsychiatric Inventory-plus (NPI-plus), 12 items: original 10 NPI items, sleep [17, 18], and cognitive fluctuation reported as Cognitive Fluctuation Inventory $[19,20] \geq 8$, and NPI-2 (hallucinations and cognitive fluctuation [12], only in phase III) $\geq 1$ ]. The evidence or rationale for the presence of the core features, on which each diagnosis of DLB was based, was provided and examined by the review board (Mori, Ikeda, and Kosaka) to assure the validity of the diagnosis. In the board, the rating in Short Fluctuations Questionnaire, developed based on the Mayo Fluctuation Questionnaire [21, 22], and scores in each item of the NPI and Unified Parkinson's Disease Rating Scale (UPDRS) part III [23] were also referred.

Exclusion criteria were Parkinson's disease diagnosed at least 1 year prior to the onset of dementia; focal vascular lesions on magnetic resonance imaging or computed tomography scan that might cause cognitive impairment; other neurological or psychiatric diseases; complications or a history of severe gastrointestinal ulcer, severe asthma or obstructive pulmonary disease; systolic hypotension (<90 mm Hg); bradycardia $(<50 \mathrm{bpm})$; sick sinus syndrome; atrial or atrioventricular conduction block; QT interval prolongation ( $\geq 450 \mathrm{~ms}$ ); severe parkinsonism (Hoehn and Yahr stage $\geq$ IV) [24], and treatment with the cholinesterase inhibitors (ChEIs) or any investigational drug within 3 months prior to screening. ChEIs, antipsychotics, and anti-Parkinson drugs other than levodopa or dopamine agonists were not allowed during the study. Written informed consent was obtained from the patient (if at all possible) and his/her primary family member before initiating the study procedures.

\section{Measures for Clinical Characteristics}

Severity of dementia was measured using the CDR [25]. Cognitive function was assessed with the MMSE [26]. Severity of extrapyramidal disorders was classified using the Hoehn and Yahr stage [24]. Additionally, motor functions were assessed with the UPDRS part III with a score range of 0 (no) to 108 (severe) [23]. Subscales were defined as the following four symptoms: tremor, akinesia, rigidity, and postural instability and gait difficulty with a score range of $0-36,0-28,0-20$, and $0-16$, respectively $[27,28]$.

BPSD were assessed using the NPI. The original NPI-10 includes 10 domains: delusions, hallucinations, agitation/aggression, depression/dysphoria, anxiety, elation/euphoria, apathy/indifference, disinhibition, irritability/lability, and aberrant motor behaviour [17]. Each domain is scored based on frequency and severity with a score range of $0-12$, with a maximum total score of 120 . Cognitive fluctuation was assessed using the Cognitive Fluctuation Inventory, with the same format as the original NPI [19, 20], of which content validity and reliability has been previously assured [19] (online suppl. file 1; for all online suppl. material, see www.karger.com/doi/10.1159/000441443). The NPI-2 [12] was calculated as the sum of the scores for hallucinations and cognitive fluctuation $[19,20]$, corresponding to two of the three core features of DLB, with a score range of $0-24$.

\section{Statistical Analysis}

This analysis included the full analysis set of each study, comprising all patients who received the study drug at least once and had valid efficacy assessment data at more than one point. The data of the two studies were pooled, and the data on demographics and clinical characteristics were analysed and summarised descriptively.

Subsequently, patient characteristics between the two studies were compared. The characteristics of the patients enrolled at psychiatry and neurology specialty centres, where most were enrolled, were also compared by types of centre. Fisher's exact or $\chi^{2}$ test was performed for categorical variables and test for continuous variables. Logistic regression analysis or analysis of variance was performed for interaction between the two studies and types of specialty centres.

All statistical analyses have been performed using SAS for Windows, version 9.3 (SAS Institute Inc., Cary, N.C., USA) with a two-tailed 0.05 significance level. 
Dementia

Cognitive Disorders

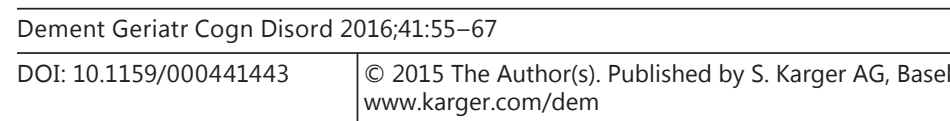

Ikeda et al.: Adequacy of Using Consensus Guidelines for Diagnosis of Dementia with Lewy Bodies in Clinical Trials for Drug Development

Table 1. Patient demographics according to studies and specialty centres

\begin{tabular}{|c|c|c|c|c|c|c|c|}
\hline & \multirow{2}{*}{$\begin{array}{l}\text { Total } \\
(n=273)\end{array}$} & \multicolumn{3}{|l|}{ Studies } & \multicolumn{3}{|c|}{ Specialty centres } \\
\hline & & $\begin{array}{l}\text { phase II } \\
(n=135)\end{array}$ & $\begin{array}{l}\text { phase III } \\
(n=138)\end{array}$ & $\mathrm{p}$ value $\mathrm{a}^{\mathrm{a}}$ & $\begin{array}{l}\text { psychiatric } \\
(\mathrm{n}=73)\end{array}$ & $\begin{array}{l}\text { neurological } \\
(\mathrm{n}=184)\end{array}$ & $p$ value \\
\hline Sex & & & & 0.213 & & & 0.006 \\
\hline Male & $104(38.1)$ & $46(34.1)$ & $58(42.0)$ & & $17(23.3)$ & $77(41.8)$ & \\
\hline Female & 169 (61.9) & $89(65.9)$ & $80(58.0)$ & & $56(76.7)$ & $107(58.2)$ & \\
\hline Mean age, years & $78.3(5.8)$ & $78.7(5.6)$ & $77.9(6.1)$ & 0.259 & $79.3(6.0)$ & $78.2(5.6)$ & 0.164 \\
\hline Mean weight, kg & $49.6(9.9)$ & $48.3(9.7)$ & $50.9(9.9)$ & 0.031 & $48.8(8.0)$ & $49.6(10.5)$ & 0.572 \\
\hline \multicolumn{8}{|l|}{$\begin{array}{l}\text { Duration since onset of cognitive } \\
\text { decline, years }\end{array}$} \\
\hline Mean (SD) & $2.3(2.2)$ & $2.3(2.4)$ & $2.3(2.0)$ & 0.851 & $2.5(1.7)$ & $2.1(2.0)$ & 0.176 \\
\hline Range & $0.0-20.4$ & $0.1-20.4$ & $0.0-10.8$ & & $0.1-7.4$ & $0.0-10.8$ & \\
\hline Experience of anti-dementia medication & $12(4.4)$ & $4(3.0)$ & $8(5.8)$ & 0.377 & $5(6.8)$ & $6(3.3)$ & 0.302 \\
\hline
\end{tabular}

Figures in parentheses indicate SD or percentage. ${ }^{a}$ Fisher's exact or $\chi^{2}$ test for categorical variables and t test for continuous variables were used.

\section{Results}

A total of 273 patients (phase II: 135, phase III: 138) from a total of 89 specialty centres were incorporated for the analysis: 73 patients were enrolled from psychiatric centres, 184 from neurological centres, and 16 from other centres such as gerontological and neurosurgical centres. Demographic characteristics are summarised in table 1.

\section{Diagnostic and Clinical Characteristics Based on the Central and Core Features (Pooled}

Analysis)

Central Feature

The central feature of DLB is progressive cognitive decline. The CDR of more than half of the patients was $1(52.4 \%)$, followed by $0.5(27.5 \%), 2(19.4 \%)$, and $3(0.7 \%$; table 2$)$. The MMSE score (mean \pm SD) was $19.4 \pm 4.2$ (table 3).

\section{Core Features}

The core features of DLB include cognitive fluctuation, visual hallucinations, and parkinsonism. Patients with the respective core features were 94.1\% (257/273), 84.6\% (231/273), and $86.4 \%$ (236/273; table 2). The proportion of patients with all three features was $65.2 \%$ (178/273). Of those with two features, the most prevalent was a combination of cognitive fluctuation and parkinsonism (15.4\%), followed by cognitive fluctuation and visual hallucinations (13.6\%) and visual hallucinations and parkinsonism (5.9\%; table 4). In the NPI-plus, cognitive fluctuation showed the highest score (mean \pm SD: $3.7 \pm 3.0$ ) and the highest proportion of patients with the symptom (score $\geq 1$ : $83.9 \%$ ) among the items (fig. 1). Hallucinations also showed a high mean score of $3.3 \pm 3.2$, the third highest following cognitive fluctuation and apathy/indifference, and the second highest proportion of patients with the symptom (score $\geq 1: 75.1 \%$ ). Regarding parkinsonism, almost half of the patients were at the Hoehn and Yahr stage III (45.3\%), followed by stage II (39.4\%) and stage I (15.3\%; table 2). The UPDRS part III score (mean \pm SD) was $19.8 \pm 11.4$, with the higher subscale scores of akinesia $(8.1 \pm 4.9)$ and rigidity $(4.2 \pm 3.2$; table 5$)$. The proportion of patients taking antiParkinson drugs was $20.1 \%$ (table 6). 
Ikeda et al.: Adequacy of Using Consensus Guidelines for Diagnosis of Dementia with Lewy Bodies in Clinical Trials for Drug Development

Table 2. Clinical characteristics of patients with DLB according to studies and specialty centres

\begin{tabular}{|c|c|c|c|c|c|c|c|}
\hline & \multirow{2}{*}{$\begin{array}{l}\text { Total } \\
(\mathrm{n}=273)\end{array}$} & \multicolumn{3}{|l|}{ Studies } & \multicolumn{3}{|c|}{ Specialty centres } \\
\hline & & $\begin{array}{l}\text { phase II } \\
(\mathrm{n}=135)\end{array}$ & $\begin{array}{l}\text { phase III } \\
(\mathrm{n}=138)\end{array}$ & $\mathrm{p}$ value $\mathrm{a}^{\mathrm{a}}$ & $\begin{array}{l}\text { psychiatric } \\
(\mathrm{n}=73)\end{array}$ & $\begin{array}{l}\text { neurological } \\
(\mathrm{n}=184)\end{array}$ & $\mathrm{p}$ value $^{\mathrm{a}}$ \\
\hline Presence of progressive cognitive decline & $273(100.0)$ & $135(100.0)$ & $138(100.0)$ & & $73(100.0)$ & $184(100.0)$ & \\
\hline CDR & & & & 0.467 & & & 0.839 \\
\hline 0.5 & $75(27.5)$ & 39 (28.9) & $36(26.1)$ & & $20(27.4)$ & $52(28.3)$ & \\
\hline 1 & $143(52.4)$ & $74(54.8)$ & $69(50.0)$ & & 38 (52.1) & 94 (51.1) & \\
\hline 2 & $53(19.4)$ & $21(15.6)$ & $32(23.2)$ & & $15(20.5)$ & $36(19.6)$ & \\
\hline 3 & $2(0.7)$ & $1(0.7)$ & $1(0.7)$ & & 0 & $2(1.1)$ & \\
\hline Cognitive fluctuation & $257(94.1)$ & $130(96.3)$ & $127(92.0)$ & 0.197 & $72(98.6)$ & $170(92.4)$ & 0.074 \\
\hline Visual hallucinations & $231(84.6)$ & $111(82.2)$ & $120(87.0)$ & 0.316 & $63(86.3)$ & $155(84.2)$ & 0.847 \\
\hline Parkinsonism & $236(86.4)$ & $115(85.2)$ & $121(87.7)$ & 0.598 & $52(71.2)$ & $169(91.8)$ & $<0.001$ \\
\hline Hoehn and Yahr stage & & & & 0.587 & & & $<0.001$ \\
\hline I & $36(15.3)$ & $17(14.8)$ & $19(15.7)$ & & $13(25.0)$ & $19(11.2)$ & \\
\hline II & $93(39.4)$ & $42(36.5)$ & $51(42.1)$ & & $28(53.8)$ & 57 (33.7) & \\
\hline III & $107(45.3)$ & $56(48.7)$ & $51(42.1)$ & & $11(21.2)$ & $93(55.0)$ & \\
\hline$\geq \mathrm{IV}$ & 0 & 0 & 0 & & 0 & 0 & \\
\hline REM sleep behaviour disorder & $107(39.2)$ & $52(38.5)$ & $55(39.9)$ & 0.901 & $27(37.0)$ & $70(38.0)$ & 1.000 \\
\hline Neuroleptic sensitivity & $14(5.1)$ & $7(5.2)$ & $7(5.1)$ & 1.000 & $4(5.5)$ & $9(4.9)$ & 1.000 \\
\hline SPECT or PET scan within 3 years prior to consent & $142(52.0)$ & $88(65.2)$ & $54(39.1)$ & $<0.001$ & $28(38.4)$ & $107(58.2)$ & 0.005 \\
\hline Flow decline in occipital lobe and metabolic decline & $118(83.1)$ & $74(84.1)$ & $44(81.5)$ & 0.687 & $23(82.1)$ & $88(82.2)$ & 0.990 \\
\hline Myocardial scintigraphy within 3 years prior to consent & $78(28.6)$ & 37 (27.4) & $41(29.7)$ & 0.690 & $8(11.0)$ & $68(37.0)$ & $<0.001$ \\
\hline Decreased myocardial uptake of MIBG & $70(89.7)$ & $31(83.8)$ & 39 (95.1) & 0.141 & $8(100.0)$ & $60(88.2)$ & 0.589 \\
\hline Repeated falls and syncope & $56(20.5)$ & $29(21.5)$ & 27 (19.6) & 0.765 & $14(19.2)$ & $41(22.3)$ & 0.618 \\
\hline Transient loss of consciousness & $21(7.7)$ & $11(8.1)$ & $10(7.2)$ & 0.823 & $3(4.1)$ & $18(9.8)$ & 0.205 \\
\hline Severe autonomic dysfunction & $61(22.3)$ & $27(20.0)$ & $34(24.6)$ & 0.386 & $13(17.8)$ & $43(23.4)$ & 0.403 \\
\hline Hallucinations in other modalities & $103(37.7)$ & $53(39.3)$ & $50(36.2)$ & 0.620 & $28(38.4)$ & $71(38.6)$ & 1.000 \\
\hline Systematised delusion & $93(34.1)$ & $44(32.6)$ & $49(35.5)$ & 0.702 & $21(28.8)$ & $69(37.5)$ & 0.196 \\
\hline Depression & $103(37.7)$ & $55(40.7)$ & $48(34.8)$ & 0.321 & $26(35.6)$ & $71(38.6)$ & 0.672 \\
\hline
\end{tabular}

Totals may not sum to $100 \%$ owing to rounding. Data are presented as n (\%). REM $=$ Rapid eye movement. ${ }^{a}$ Fisher's exact or $\chi^{2}$ test for categorical variables and $t$ test for continuous variables were used.

Table 3. Assessment of cognitive, neuropsychiatric, and behavioural function in patients with DLB according to studies and specialty centres

\begin{tabular}{|c|c|c|c|c|c|c|c|}
\hline & \multirow{2}{*}{$\begin{array}{l}\text { Total } \\
(n=273)\end{array}$} & \multicolumn{3}{|l|}{ Studies } & \multicolumn{3}{|c|}{ Specialty centres } \\
\hline & & $\begin{array}{l}\text { phase II } \\
(\mathrm{n}=135)\end{array}$ & $\begin{array}{l}\text { phase III } \\
(n=138)\end{array}$ & $\mathrm{p}$ value $\mathrm{a}^{\mathrm{a}}$ & $\begin{array}{l}\text { psychiatric } \\
(\mathrm{n}=73)\end{array}$ & $\begin{array}{l}\text { neurological } \\
(\mathrm{n}=184)\end{array}$ & p value ${ }^{a}$ \\
\hline MMSE at screening & $19.4 \pm 4.2$ & $19.4 \pm 4.3$ & $19.4 \pm 4.1$ & 0.996 & $19.3 \pm 4.4$ & $19.6 \pm 4.1$ & 0.606 \\
\hline MMSE & & & & 0.855 & & & 0.483 \\
\hline$\leq 17$ & $79(28.9)$ & 39 (28.9) & $40(29.0)$ & & $21(28.8)$ & $54(29.3)$ & \\
\hline$\geq 18, \leq 21$ & $99(36.3)$ & $47(34.8)$ & $52(37.7)$ & & $30(41.1)$ & $62(33.7)$ & \\
\hline$\geq 22$ & $95(34.8)$ & $49(36.3)$ & $46(33.3)$ & & $22(30.1)$ & $68(37.0)$ & \\
\hline NPI-2 at baseline & $7.0 \pm 4.6$ & $6.9 \pm 4.6$ & $7.1 \pm 4.5$ & 0.833 & $7.8 \pm 4.5$ & $6.8 \pm 4.5$ & 0.112 \\
\hline NPI-2 & & & & 0.784 & & & 0.208 \\
\hline$\leq 4$ & $106(38.8)$ & $52(38.5)$ & $54(39.1)$ & & $22(30.1)$ & $76(41.3)$ & \\
\hline$\geq 5, \leq 8$ & $82(30.0)$ & 43 (31.9) & 39 (28.3) & & $23(31.5)$ & $54(29.3)$ & \\
\hline$\geq 9$ & $85(31.1)$ & $40(29.6)$ & $45(32.6)$ & & $28(38.4)$ & $54(29.3)$ & \\
\hline NPI-10 & $18.4 \pm 12.7$ & $18.2 \pm 11.2$ & $18.6 \pm 14.0$ & 0.809 & $19.8 \pm 12.4$ & $17.6 \pm 12.3$ & 0.188 \\
\hline
\end{tabular}

Totals may not sum to $100 \%$ owing to rounding. Data are presented as mean \pm SD or $n(\%)$. ${ }^{a}$ Fisher's exact test for categorical variables and $\mathrm{t}$ test for continuous variables were used. 
Dementia

Cognitive Disorders

\begin{tabular}{l|l}
\hline Dement Geriatr Cogn Disord 2016:41:55-67 \\
\hline DOI: 10.1159/000441443 & $\begin{array}{l}\text { (c) 2015 The Author(s). Published by S. Karger AG, Basel } \\
\text { www.karger.com/dem }\end{array}$
\end{tabular}

Ikeda et al.: Adequacy of Using Consensus Guidelines for Diagnosis of Dementia with Lewy Bodies in Clinical Trials for Drug Development

Table 4. Core features of symptoms in patients with DLB at baseline according to studies and specialty centres

\begin{tabular}{llllll}
$\begin{array}{l}\text { Total } \\
(\mathrm{n}=273)\end{array}$ & Studies & & \multicolumn{3}{l}{ Specialty centres } \\
\cline { 2 - 3 } & $\begin{array}{l}\text { phase II } \\
(\mathrm{n}=135)\end{array}$ & $\begin{array}{l}\text { phase III } \\
(\mathrm{n}=138)\end{array}$ & $\begin{array}{l}\text { psychiatric } \\
(\mathrm{n}=73)\end{array}$ & $\begin{array}{l}\text { neurological } \\
(\mathrm{n}=184)\end{array}$ & $\begin{array}{l}\text { others } \\
(\mathrm{n}=16)\end{array}$
\end{tabular}

Three symptoms: cognitive fluctuation, visual hallucinations, parkinsonism

Two symptoms: cognitive fluctuation, visual hallucinations

\begin{tabular}{lccccc}
$178(65.2)$ & $86(63.7)$ & $92(66.7)$ & $41(56.2)$ & $126(68.5)$ & $11(68.8)$ \\
& & & & & \\
$37(13.6)$ & $20(14.8)$ & $17(12.3)$ & $21(28.8)$ & $15(8.2)$ & $1(6.3)$ \\
$42(15.4)$ & $24(17.8)$ & $18(13.0)$ & $10(13.7)$ & $29(15.8)$ & $3(18.8)$ \\
$16(5.9)$ & $5(3.7)$ & $11(8.0)$ & $1(1.4)$ & $14(7.6)$ & $1(6.3)$ \\
\hline
\end{tabular}

Two symptoms: cognitive fluctuation, parkinsonism

Two symptoms: visual hallucinations, parkinsonism

Totals may not sum to $100 \%$ owing to rounding. Data indicate frequency (\%).

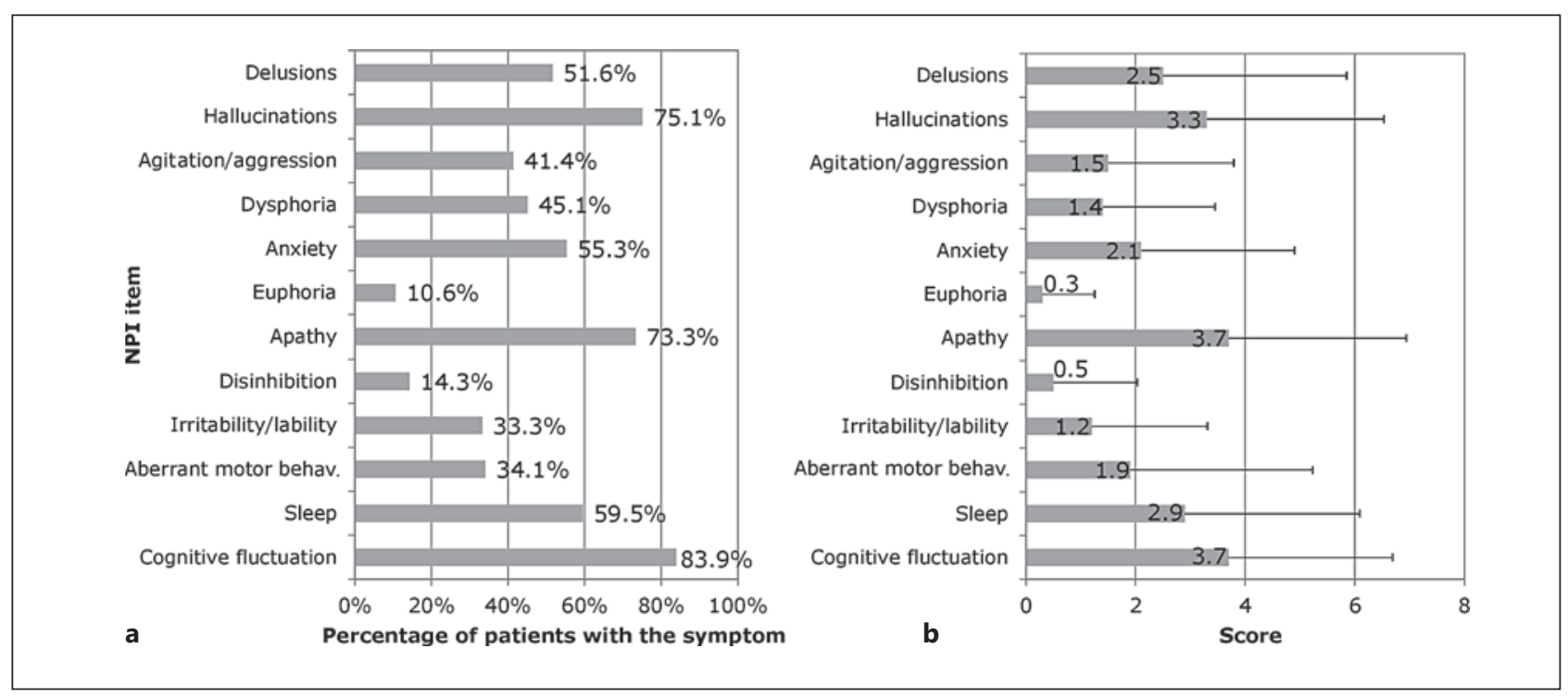

Fig. 1. a Proportions of patients with the presence of NPI symptoms. b Mean NPI scores of individual items. $\mathrm{T}$ bars indicate standard deviation.

\section{Prevalence of Suggestive and Supportive Features (Pooled Analysis)}

Suggestive Features

Patients commonly experienced the rapid eye movement sleep behaviour disorder (RBD; $39.2 \%$ ) while rarely experiencing neuroleptic sensitivity (5.1\%; table 2). Dopamine transporter uptake was not assessed as DaTscan was not approved at the time of study implementation in Japan.

\section{Supportive Features}

Patients commonly experienced the following three symptoms: hallucinations in other modalities (37.7\%), depression (37.7\%), and systematised delusion (34.1\%; table 2). Compared with these psychiatric symptoms, prevalence of repeated falls and syncope $(20.5 \%)$, transient loss of consciousness (7.7\%), and severe autonomic dysfunction (22.3\%) were relatively low. Single-photon emission computed tomography (SPECT) or positron emission tomography (PET) scan was performed in $52.0 \%$ (table 2). Of these, decreased cerebral blood flow or metabolism in the occipital lobes was observed in $83.1 \%$. Similarly, myocardial scin- 
Ikeda et al.: Adequacy of Using Consensus Guidelines for Diagnosis of Dementia with Lewy Bodies in Clinical Trials for Drug Development

Table 5. Assessment of UPDRS part III in DLB patients according to studies and specialty centres

\begin{tabular}{|c|c|c|c|c|c|c|c|}
\hline & \multirow{2}{*}{$\begin{array}{l}\text { Total } \\
(n=273)\end{array}$} & \multicolumn{3}{|l|}{ Studies } & \multicolumn{3}{|c|}{ Specialty centres } \\
\hline & & $\begin{array}{l}\text { phase II } \\
(n=135)\end{array}$ & $\begin{array}{l}\text { phase III } \\
(n=138)\end{array}$ & $\mathrm{p}$ value $^{\mathrm{a}}$ & $\begin{array}{l}\text { psychiatric } \\
(n=73)\end{array}$ & $\begin{array}{l}\text { neurological } \\
(n=184)\end{array}$ & $\mathrm{p}$ value $^{\mathrm{a}}$ \\
\hline Total score & $19.8(11.4)$ & $19.3(10.5)$ & $20.4(12.2)$ & 0.425 & $18.8(12.5)$ & $20.5(10.9)$ & 0.296 \\
\hline Tremor $^{b}$ & $2.1(3.1)$ & $2.1(3.1)$ & $2.1(3.1)$ & 0.943 & $3.3(3.9)$ & $1.6(2.5)$ & $<0.001$ \\
\hline Akinesia $^{c}$ & $8.1(4.9)$ & $7.8(4.6)$ & $8.4(5.2)$ & 0.322 & $7.7(5.2)$ & $8.4(4.9)$ & 0.345 \\
\hline Rigidity $^{\mathrm{d}}$ & $4.2(3.2)$ & $3.9(2.9)$ & $4.4(3.5)$ & 0.194 & $3.1(3.1)$ & $4.6(3.3)$ & 0.001 \\
\hline $\begin{array}{l}\text { Postural instability and gait } \\
\text { difficulty }\end{array}$ & $3.5(2.6)$ & $3.4(2.5)$ & $3.5(2.7)$ & 0.941 & $2.9(2.7)$ & $3.7(2.6)$ & 0.017 \\
\hline
\end{tabular}

Data indicate mean (SD). ${ }^{\mathrm{a}} \mathrm{T}$ test was used for statistical significance. ${ }^{\mathrm{b}}$ Tremor includes tremor at rest (face, both sides of hands and feet) and action or postural tremor of hands (right and left), ranging from 0 to 28. ${ }^{c}$ Akinesia includes finger taps (left), finger taps (right), hand movement (left), hand movement (right), rapid altering movements of hands (left), rapid altering movements of hands (right), leg agility (left), leg agility (right), and body bradykinesia and hypokinesia, ranging from 0 to 36.

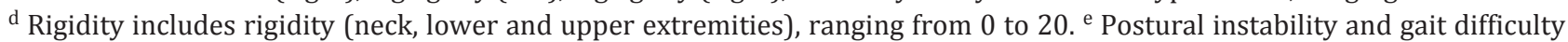
includes rising from chair, posture erect, gait, and postural stability, ranging from 0 to 16.

Table 6. Concomitant drug at baseline in DLB patients according to studies and specialty centres

\begin{tabular}{|c|c|c|c|c|c|c|c|}
\hline & \multirow{2}{*}{$\begin{array}{l}\text { Total } \\
(n=273)\end{array}$} & \multicolumn{3}{|l|}{ Studies } & \multicolumn{3}{|c|}{ Specialty centres } \\
\hline & & $\begin{array}{l}\text { phase II } \\
(n=135)\end{array}$ & $\begin{array}{l}\text { phase III } \\
(n=138)\end{array}$ & $\mathrm{p}$ value $\mathrm{a}^{\mathrm{a}}$ & $\begin{array}{l}\text { psychiatric } \\
(n=73)\end{array}$ & $\begin{array}{l}\text { neurological } \\
(n=184)\end{array}$ & $\mathrm{p}$ value \\
\hline Anti-Parkinson drugs ${ }^{b}$ & $55(20.1)$ & $24(17.8)$ & $31(22.5)$ & 0.367 & $8(11.0)$ & $45(24.5)$ & 0.017 \\
\hline Anti-depressants & $19(7.0)$ & $9(6.7)$ & $10(7.2)$ & 1.000 & $4(5.5)$ & $14(7.6)$ & 0.787 \\
\hline Anxiolytics & $43(15.8)$ & $19(14.1)$ & $24(17.4)$ & 0.508 & $16(21.9)$ & $26(14.1)$ & 0.137 \\
\hline Hypnotics & $48(17.6)$ & $21(15.6)$ & $27(19.6)$ & 0.428 & $14(19.2)$ & $32(17.4)$ & 0.722 \\
\hline Cerebral metabolism enhancer & $20(7.3)$ & $8(5.9)$ & $12(8.7)$ & 0.487 & $2(2.7)$ & $17(9.2)$ & 0.110 \\
\hline
\end{tabular}

Data indicate $\mathrm{n}(\%) .{ }^{\mathrm{a}}$ Fisher's exact test was used for statistical significance. ${ }^{\mathrm{b}}$ Levodopa or dopamine agonists.

tigraphy was performed in $28.6 \%$. Of these, decreased myocardial uptake of ${ }^{123}$ I-metaiodobenzylguanidine (MIBG) was observed in $89.7 \%$. On magnetic resonance imaging or computed tomography scan, $12.8 \%$ showed no atrophy of the cerebral cortex including medial temporal lobe, and $64.8 \%$ showed mild atrophy. Data on electroencephalography were not required.

\section{Other Clinical Features}

The NPI-10 score (mean \pm SD) was $18.4 \pm 12.7$ (table 3 ). Among the NPI-plus items, the mean score was highest in cognitive fluctuation $(3.7 \pm 3.0)$ and apathy/indifference $(3.7 \pm$ $3.2)$, followed by hallucinations ( $3.3 \pm 3.2)$, sleep $(2.9 \pm 3.2)$, delusions $(2.5 \pm 3.4)$ and anxiety $(2.1 \pm 2.8$; fig. 1$)$. The proportion of patients with the symptom (score $\geq 1$ ) was highest in cognitive fluctuation (83.9\%), followed by hallucinations (75.1\%), apathy/indifference (73.3\%), sleep (59.5\%), and anxiety (55.3\%).

\section{Comparison of Patient Characteristics between the Phase II and III Studies}

Central Feature

The proportions of the CDR 1 were 54.8 and $50.0 \%$ in phases II and III, respectively (table 2). The MMSE scores (mean \pm SD) were $19.4 \pm 4.3$ and 19.4 \pm 4.1 , respectively (table 3 ). 
Ikeda et al.: Adequacy of Using Consensus Guidelines for Diagnosis of Dementia with Lewy Bodies in Clinical Trials for Drug Development

There was no difference in the distribution of the CDR and MMSE score between the two studies $(\mathrm{p}=0.467$ and 0.996$)$.

\section{Core Features}

Patients with cognitive fluctuation, visual hallucinations, and parkinsonism were 96.3, 82.2 , and $85.2 \%$ in phase II, and $92.0,87.0$, and $87.7 \%$ in phase III, respectively, with no significant differences between the studies (table 2). Patients with all core features were 63.7 and $66.7 \%$, respectively (table 4 ). In the NPI-plus, the scores (mean \pm SD) of cognitive fluctuation were $3.4 \pm 3.0$ and $3.9 \pm 3.0$, respectively, and those of hallucinations were $3.5 \pm 3.4$ and $3.1 \pm$ 3.0 , respectively, with no significant differences between the studies $(\mathrm{p}=0.151,0.304)$. Regarding parkinsonism, patients at the Hoehn and Yahr stage III were 48.7 and $42.1 \%$ in phases II and III, respectively (table 2). The UPDRS part III scores (mean \pm SD) were $19.3 \pm 10.5$ and $20.4 \pm 12.2$, respectively (table 5). There was no difference in the distribution of the Hoehn and Yahr stage and UPDRS part III score between the two studies ( $\mathrm{p}=0.587,0.425)$. The use of anti-Parkinson drugs was also similar: 17.8 and $22.5 \%$, respectively $(p=0.367$; table 6$)$.

Other Clinical Features

Regarding suggestive or supportive features, no significant differences were found (table 2). A SPECT or PET scan was performed in more patients in phase II (65.2 vs. 39.1\%, $\mathrm{p}<0.001$ ), but decreased cerebral blood flow and metabolism in the occipital lobes were observed in similar proportions. Mean NPI-10 scores were $18.2 \pm 11.2$ and $18.6 \pm 14.0$ in phases II and III, respectively (table 3 ). The proportions of patients taking concomitant medications (anti-depressants, anxiolytics, hypnotics, and cerebral metabolism enhancers) were also similar between the studies (table 6).

\section{Comparisons of Patient Characteristics between Psychiatric and Neurological Specialty}

Centres

Central Feature

The proportions of the CDR 1 were 52.1 and $51.1 \%$ in the psychiatric and neurological centres, respectively (table 2). The MMSE scores (mean \pm SD) were $19.3 \pm 4.4$ and 19.6 \pm 4.1 , respectively (table 3 ). There was no difference in the distribution of the CDR and MMSE score between types of centres ( $p=0.839,0.606)$.

\section{Core Features}

Patients with cognitive fluctuation, visual hallucinations, and parkinsonism were 98.6, 86.3 , and $71.2 \%$ in the psychiatric centres, and $92.4,84.2$, and $91.8 \%$ in the neurological centres, respectively. The proportion of patients with parkinsonism was significantly higher in the neurological centres ( $p<0.001$; table 2). More patients with all core features tended to be enrolled from the neurological centres (68.5\%) than psychiatric centres $(56.2 \%, \mathrm{p}=0.081$; table 4). Conversely, those with a combination of cognitive fluctuation and visual hallucinations were enrolled more in psychiatric centres $(28.8$ and $8.2 \%, \mathrm{p}<0.001)$. In the NPI-plus, the scores (mean \pm SD) of cognitive fluctuation were $3.8 \pm 3.1$ and $3.6 \pm 2.9$, respectively, and those of hallucinations were $3.9 \pm 3.6$ and $3.1 \pm 3.1$, respectively, with no significant differences between types of centres ( $\mathrm{p}=0.649,0.073)$. Regarding parkinsonism, patients at Hoehn and Yahr stage III were 21.2 and $55.0 \%$ in the psychiatric and neurological centres, with a significant difference in the distribution of the stage between them $(\mathrm{p}<0.001$; table 2$)$. The UPDRS part III score (mean \pm SD) was not different between types of centres (18.8 \pm 12.5 and $20.5 \pm 10.9$, respectively, $\mathrm{p}=0.296$ ); the subscores of rigidity and postural instability and gait difficulty were higher in neurological centres, and that of tremor was higher in psychiatric centres (table 5). Interaction was found in rigidity (neurological: phase II < III, psychiatric: 
Dementia

and Geriatric

Cognitive Disorders \begin{tabular}{l|l}
\hline Dement Geriatr Cogn Disord 2016;41:55-67 \\
\hline DOI: 10.1159/000441443 & $\begin{array}{l}\text { (c) 2015 The Author(s). Published by S. Karger AG, Basel } \\
\text { www.karger.com/dem }\end{array}$ \\
\hline
\end{tabular}

Ikeda et al.: Adequacy of Using Consensus Guidelines for Diagnosis of Dementia with Lewy Bodies in Clinical Trials for Drug Development

phase II > III, p = 0.039), with a significant difference between centres only in phase III. The proportion of patients taking anti-Parkinson medications was also significantly higher in the neurological centres (24.5 and $11.0 \%, \mathrm{p}=0.017$; table 6).

Other Clinical Features

Regarding suggestive and supportive features, no significant differences were observed between types of centres (table 2). Myocardial scintigraphy was performed in more patients in the neurological $(37.0 \%)$ than psychiatric centres $(11.0 \%$; $<<0.001)$, but decreased myocardial uptake of MIBG was observed in similar proportion. The NPI-10 scores (mean \pm SD) were $19.8 \pm 12.4$ and $17.6 \pm 12.3$ in the psychiatric and neurological centres, respectively (table 3). The proportions of patients taking concomitant medications were also similar between types of centres, although the proportion of patients with concomitant anti-anxiety drugs was slightly higher in the psychiatric centres, but this was not significant (21.9 vs. $14.1 \%$, respectively; table 6).

\section{Discussion}

We explored clinical characteristics of patients with DLB using data from the previous phase II and III studies of donepezil for DLB. The results provided detailed descriptions of clinical characteristics of patients with probable DLB based on the original consensus diagnostic criteria [2] and showed a high prevalence of the suggestive and supportive items of the revised criteria [3] in those patients. Furthermore, overall, similar patient characteristics were found between types of specialty centres as well as varying times of study implementation.

Only a few large-scale clinical trials for DLB have been conducted. Compared with AD, it is difficult to enrol a large number of patients into clinical trials, especially RCTs, for DLB owing to its faster progression, wide variety of symptoms including severe BPSD, greater caregiver burden, and easily induced severe adverse events [11,29-32]. In the previous two RCTs of donepezil, the number of patients enrolled by each centre was generally small (none by 5 and only 1 patient by 14 out of 48 centres in phase II, and none by 14 and only 1 patient by 15 out of 72 centres in phase III). Similar recruitment difficulties impeded an RCT of rivastigmine for DLB [33]. It might be inevitable that patients are recruited from various specialty departments, such as neurology, psychiatry, geriatrics, and so on, of multinational centres for future RCTs in DLB and that enrolment in those studies takes a long time. Therefore, it is very important to confirm the adequacy of using the consensus criteria in those studies by comparing patient characteristics among trials conducted at different times and subjects enrolled from different types of specialty centres.

The phase III study of donepezil was initiated about 3 years after initiating phase II. Nevertheless, patient characteristics of these trials were almost the same except for the proportion of patients in whom a SPECT or PET scan was performed. This difference may be due to the high proportion of patients from clinics and the low proportion from hospitals in phase III.

Clinical characteristics were also similar between psychiatric and neurological centres. The only exception was parkinsonism, specifically the proportions of patients with parkinsonism and in concomitant use of anti-Parkinson medication, and the severity assessed with the Hoehn and Yahr stage, which were significantly higher in neurological centres, as expected. In psychiatric centres, a larger proportion of patients were diagnosed as probable DLB with two core features: cognitive fluctuation and visual hallucinations. The NPI-10 score and the proportion of patients with concomitant administration of anti-anxiety drugs were relatively higher in psychiatric than neurological centres, but the differences were not significant and no difference in any subscale of NPI was also found between them. This may suggest that 
Ikeda et al.: Adequacy of Using Consensus Guidelines for Diagnosis of Dementia with Lewy Bodies in Clinical Trials for Drug Development

patients from psychiatric centres developed anxiety more frequently than those from neurology centres before the entry into the studies.

Core features observed in these studies were also not greatly different from those in the RCTs of rivastigmine conducted in 2000 or earlier in Spain, the UK, and Italy: cognitive fluctuation, 90\%; visual hallucinations, 78\%; parkinsonism, 90\%, and mean MMSE score, approximately 18 [33].

These findings suggest that the consensus diagnostic criteria are reliable and can be used to enrol patients with homogeneous characteristics in clinical trials, which various specialty departments of a large number of multinational centres join with a long enrolment period. They also imply that similar proportions of neurological and psychiatric centres should be included because the presence/absence and severity of parkinsonism may vary depending upon specialty centres.

More than a decade has passed since the consensus diagnostic criteria and their revised version were published $[2,3]$. During those years, clinical, neuroimaging, and molecular biological techniques have progressed, leading to major updates in diagnostic criteria for other degenerative dementias, such as $\mathrm{AD}$ and behavioural variant frontotemporal dementia. Likewise, updates in the criteria for DLB can be expected. Exploring the prevalence of suggestive as well as supportive features of the current revised criteria for DLB in subjects selected in a strictly controlled environment may be beneficial.

Among the suggestive features, RBD developed in $39.2 \%$ of patients. RBD preceded the diagnosis of DLB in almost all cases in which RBD was noted [34], and it was reported that inclusion of RBD as a core clinical feature improved the diagnostic accuracy of autopsyconfirmed DLB [8]. Furthermore, a screening questionnaire for RBD in patients with dementia was recently developed [35]. It seems appropriate that RBD was upgraded to a suggestive feature in the revised criteria [3]. On the other hand, neuroleptic sensitivity was observed in only $5.1 \%$. This might be due to prohibition of antipsychotics during the studies. However, administration of antipsychotics has not been encouraging in a clinical setting since antipsychotics were reportedly associated with increased mortality in elderly patients with dementia. Furthermore, in DLB, hypersensitivity to them has been widely acknowledged, so that atypical antipsychotics, such as quetiapine, olanzapine, clozapine, aripiprazole, which trigger less extrapyramidal symptoms, are selected for patients with DLB if needed. Neuroleptic sensitivity is clinically important, but further research may be needed to evaluate its importance in the future diagnostic criteria.

Of the supportive features, psychiatric symptoms, such as hallucinations in other modalities, depression, and systematised delusion, were observed in approximately $35 \%$ of patients. Results of the NPI indicate that anxiety, which has a lower prevalence in other forms of dementia [36-38], was observed in 55.3\%, suggesting that this could be added to the diagnostic criteria. Interestingly, an earlier research found that anxiety was a risk factor for DLB [39]. A relatively high prevalence of both repeated falls and syncope (20.5\%) and severe autonomic dysfunction $(22.3 \%)$ was observed, unlike transient loss of consciousness $(7.7 \%)$. Although imaging tests were not conducted in all patients, decreased cerebral blood flow and metabolism in the occipital lobes and decreased myocardial uptake were found positive in 83.1 and $89.7 \%$, respectively, implying the importance of these items in the criteria.

The present analysis has some limitations. The data were originally collected under a clinical trial setting where strict criteria were employed. In particular, to examine the effect of donepezil on BPSD, the inclusion criteria in 2 studies required at least some degree of BPSD. Furthermore, due to concerns about safety, patients with severe parkinsonism (Hoehn and Yahr stage $\geq$ IV) were excluded. As a result, patients in these studies may be more homogeneous than those in a real-life setting. Future research is needed for further application of the consensus criteria in a real-life setting. Second, among centres which participated in phase II, 
Ikeda et al.: Adequacy of Using Consensus Guidelines for Diagnosis of Dementia with Lewy Bodies in Clinical Trials for Drug Development

31 centres again joined in phase III (total 72 centres) and enrolled 73 out of a total of 138 patients. This may add the possibility that patients with similar clinical profiles tended to be enrolled. Future research without duplicated centres in enrolment may strengthen the present findings. Third, we cannot discuss the adequacy and prevalence of the central and core features because these symptoms are part of the diagnosis process. The prevalence of low dopamine transporter uptake in basal ganglia, one of the suggestive features, was not assessed as DaTscan was not approved at the time of study implementation in Japan. Lastly, regardless of relatively higher values in most parkinsonism-related indices in neurological centres, the UPRDS part III subscore of tremor was solely higher in psychiatric centres. Therefore, there might be a difference in the types of parkinsonian symptoms at the time of patients' centre visit between types of centres. Given that tremor is relatively easy to detect, however, we also cannot deny the possibility that this could be attributed to the difference in training background and hence the sensitivity of the investigators to parkinsonian symptoms, although a rater training for psychiatrists who were less experienced in scoring the UPDRS part III was provided prior to each trial to reduce such variability.

In conclusion, patient characteristics were similar between the phase II and III studies conducted 3 years apart. They were also similar between psychiatric and neurological specialty centres, with the exception of parkinsonism, which was more distinctively observed in neurological centres, reflecting specific characteristics of the specialty centres. The results of the present analysis suggest that it is adequate to employ the consensus criteria in order to enrol homogeneous DLB patients into future clinical trials regardless of the specialty of centres. A few points such as including anxiety for future revision of the consensus criteria may be open to further discussion.

\section{Acknowledgements}

We thank all patients and caregivers for their participation in our early studies; all investigators and their site staff for their contributions; Clinical Study Support Inc. for their editorial assistance in preparing the manuscript, and the Eisai study team for their assistance. The studies and analyses were sponsored by Eisai Co., Ltd. (Tokyo, Japan). The sponsor was involved in the study design, collection and analysis of data, and review of the manuscript.

\section{Disclosure Statement}

M.I. received personal fees from Eisai during the conduct of the studies; grants and personal fees from Daiichi Sankyo, Eisai, FUJIFILM RI, Janssen, Nihonmediphysics, Novartis, Pfizer, Takeda, and Tsumura, and personal fees from MSD, Ono Pharmaceutical, and Yoshitomi outside the submitted work. E.M. received personal fees from Eisai during the conduct of the studies; grants and personal fees from Eisai, Daiichi Sankyo, and FUJIFILM RI, and personal fees from Janssen, Johnson and Johnson, Lundbeck, Novartis, Ono, Nihonmediphysics, and Medtronic outside the submitted work. E.I. received grants/grants pending from Eisai, Nihonmediphysics, Ono, and Takeda, and personal fees from Eisai, Janssen, Nihonmediphysics, Novartis, and Takeda. S.K. received personal fees from Eisai, FP, Janssen, Nihonmediphysics, Novartis, Ono, and Takeda. Y.H. received grants and/or personal fees from Amgen-Asteras, Bayer, Bristol, Dai-ichi, Dainippon-Sumitomo, Eisai, Eli-Lilly, FP, GlaxoSmithKline, Janssen, Kyowa-Kirin, MSD, Novartis, Ono, Otsuka, Takeda, and Teijin. M.H. received grants/grants pending and personal fees from Novartis, and personal fees from Daiichi Sankyo, Eisai, FUJIFILM RI, Janssen, Nihonmediphysics, and Pfizer. H.M. and M.N. are employees of Eisai. K.K. received personal fees from Eisai during the conduct of the studies, and personal fees from Tsumura, Eisai, Janssen, FUJIFILM RI, Novartis, Nihonmediphysics, Daiichi Sankyo, Ono, Otsuka, and Dainippon Sumitomo outside the submitted work.

All grants stated above were for their departments, and the authors received these as the directors of their departments. 
Ikeda et al:: Adequacy of Using Consensus Guidelines for Diagnosis of Dementia with Lewy Bodies in Clinical Trials for Drug Development

\section{References}

1 McKeith I, Mintzer J, Aarsland D, Burn D, Chiu H, Cohen-Mansfield J, Dickson D, Dubois B, Duda JE, Feldman H, Gauthier S, Halliday G, Lawlor B, Lippa C, Lopez OL, Carlos Machado J, O’Brien J, Playfer J, Reid W: International Psychogeriatric Association Expert Meeting on DLB. Dementia with Lewy bodies. Lancet Neurol 2004;3: 19-28.

2 McKeith IG, Galasko D, Kosaka K, Perry EK, et al: Consensus guidelines for the clinical and pathologic diagnosis of dementia with Lewy bodies (DLB): report of the consortium on DLB international workshop. Neurology 1996; 47:1113-1124.

3 McKeith IG, Dickson DW, Lowe J, Emre M, et al: Diagnosis and management of dementia with Lewy bodies: third report of the DLB Consortium. Neurology 2005;65:1863-1872.

4 American Psychiatric Association: Diagnostic and Statistical Manual of Mental Disorders, ed 5, revised. Arlington, American Psychiatric Association, 2013.

5 Boot BP, McDade EM, McGinnis SM, Boeve BF: Treatment of dementia with Lewy bodies. Curr Treat Options Neurol 2013;15:738-764.

6 Litvan I, Bhatia KP, Burn DJ, Goetz CG, Lang AE, McKeith I, Quinn N, Sethi KD, Shults C, Wenning GK; Movement Disorders Society Scientific Issues Committee: Movement Disorders Society Scientific Issues Committee report: SIC Task Force appraisal of clinical diagnostic criteria for Parkinsonian disorders. Mov Disord 2003; 18:467-486.

7 Nelson PT, Jicha GA, Kryscio RJ, Abner EL, Schmitt FA, Cooper G, Xu LO, Smith CD, Markesbery WR: Low sensitivity in clinical diagnoses of dementia with Lewy bodies. J Neurol 2010;257:359-366.

8 Ferman TJ, Boeve BF, Smith GE, Lin SC, Silber MH, Pedraza O, Wszolek Z, Graff-Radford NR, Uitti R, Van Gerpen J, Pao W, Knopman D, Pankratz VS, Kantarci K, Boot B, Parisi JE, Dugger BN, Fujishiro H, Petersen RC, Dickson DW: Inclusion of RBD improves the diagnostic classification of dementia with Lewy bodies. Neurology 2011; 77:875-882.

9 Huang Y, Halliday G: Can we clinically diagnose dementia with Lewy bodies yet? Transl Neurodegener 2013; 2:4.

10 O’Brien JT, Burns A; BAP Dementia Consensus Group: Clinical practice with anti-dementia drugs: a revised (second) consensus statement from the British Association for Psychopharmacology. J Psychopharmacol 2011;25:997-1019.

11 Lee DR, McKeith I, Mosimann U, Ghosh-Nodyal A, Thomas AJ: Examining carer stress in dementia: the role of subtype diagnosis and neuropsychiatric symptoms. Int J Geriatr Psychiatry 2013;28:135-141.

12 Mori E, Ikeda M, Kosaka K; Donepezil-DLB Study Investigators: Donepezil for dementia with Lewy bodies: a randomized, placebo-controlled trial. Ann Neurol 2012;72:41-52.

13 Ikeda M, Mori E, Kosaka K, Iseki E, Hashimoto M, Matsukawa N, Matsuo K, Nakagawa M; Donepezil-DLB Study Investigators: Long-term safety and efficacy of donepezil in patients with dementia with Lewy bodies: results from a 52-week, open-label, multicenter extension study. Dement Geriatr Cogn Disord 2013;36:229-241.

14 Ikeda M, Mori E, Matsuo K, Nakagawa M, Kosaka K: Donepezil for dementia with Lewy bodies: a randomized, placebo-controlled, confirmatory phase III trial. Alzheimers Res Ther 2015;7:4.

15 Mori E, Ikeda M, Nagai R, Nagai R, Matsuo K, Nakagawa M, Kosaka K: Long-term donepezil use for dementia with Lewy bodies: results from an open-label extension of Phase III trial. Alzheimers Res Ther 2015; 7:5.

16 Mori E, Ikeda M, Nakagawa M, Miyagishi H, Yamaguchi H, Kosaka K: Effects of donepezil on extrapyramidal symptoms in patients with dementia with Lewy bodies: a secondary pooled analysis of two randomizedcontrolled and two open-label long-term extension studies. Dement Geriatr Cogn Disord 2015;40:186-198.

17 Cummings JL, Mega M, Gray K, Rosenberg-Thompson S, Carusi DA, Gornbein J: The Neuropsychiatric Inventory: comprehensive assessment of psychopathology in dementia. Neurology 1994;44:2308-2314.

18 Cummings JL: The Neuropsychiatric Inventory: assessing psychopathology in dementia patients. Neurology 1997;48( suppl 6):S10-S16.

19 Hashimoto M, Manabe Y, Mori E, Hirono N, Kosaka K, Ikeda M: Content validity and inter-rater reliability of the Cognitive Fluctuation Inventory (in Japanese). Brain Nerve 2014;66:175-183.

20 Mori S, Mori E, Iseki E, Kosaka K: Efficacy and safety of donepezil in patients with dementia with Lewy bodies: preliminary findings from an open-label study. Psychiatry Clin Neurosci 2006;60:190-195.

21 Ferman TJ, Smith GE, Boeve BF, Ivnik RJ, Petersen RC, Knopman D, Graff-Radford N, Parisi J, Dickson DW: DLB fluctuations: specific features that reliably differentiate DLB from AD and normal aging. Neurology 2004;62: 181-187.

22 Nagashima A, Ichino C, Sato T, Sato A, Imamura T: Short Fluctuations Questionnaire (SFQ): a structured interview for cognitive fluctuation in dementia with Lewy bodies (DLB). Jpn J Neuropsychol 2009;25:290297.

23 Fahn S, Elton RL; UPDRS Development Committee: Unified Parkinson's Disease Rating Scale; in Fahn S, Marsden CD, Calne D, Goldstein M (eds): Recent Developments in Parkinson's Disease. Florham Park, Macmillan Healthcare Information, 1987, vol 2, pp 153-163, 293-304.

24 Hoehn MM, Yahr MD: Parkinsonism: onset, progression, and mortality. Neurology 1967;17:427-442.

25 Gelb DJ, St Laurent RT: Alternative calculation of the global clinical dementia rating. Alzheimer Dis Assoc Disord 1993;7:202-211. 
Ikeda et al.: Adequacy of Using Consensus Guidelines for Diagnosis of Dementia with Lewy Bodies in Clinical Trials for Drug Development

26 Folstein MF, Folstein SE, McHugh PR: 'Mini-mental state'. A practical method for grading the cognitive state of patients for the clinician. J Psychiatr Res 1975;12:189-198.

27 Lyoo CH, Ryu YH, Lee MJ, Lee MS: Striatal dopamine loss and discriminative sensory dysfunction in Parkinson's disease. Acta Neurol Scand 2012;126:344-349.

28 Goetz CG, Leurgans S, Raman R, Stebbins GT: Objective changes in motor function during placebo treatment in PD. Neurology 2000;54:710-714.

29 Olichney JM, Galasko D, Salmon DP, Hofstetter CR, Hansen LA, Katzman R, Thal LJ: Cognitive decline is faster in Lewy body variant than in Alzheimer's disease. Neurology 1998;51:351-357.

30 McKeith IG, Rowan E, Askew K, Naidu A, Allan L, Barnett N, Lett D, Mosimann UP, Burn D, O’Brien JT: More severe functional impairment in dementia with Lewy bodies than Alzheimer disease is related to extrapyramidal motor dysfunction. Am J Geriatr Psychiatry 2006;14:582-588.

31 Boström F, Jönsson L, Minthon L, Londos E: Patients with dementia with Lewy bodies have more impaired quality of life than patients with Alzheimer disease. Alzheimer Dis Assoc Disord 2007;21:150-154.

32 Rongve A, Vossius C, Nore S, Testad I, Aarsland D: Time until nursing home admission in people with mild dementia: comparison of dementia with Lewy bodies and Alzheimer's dementia. Int J Geriatr Psychiatry 2014; 29:392-398.

33 McKeith I, Del Ser T, Spano P, Emre M, Wesnes K, Anand R, Cicin-Sain A, Ferrara R, Spiegel R: Efficacy of rivastigmine in dementia with Lewy bodies: a randomised, double-blind, placebo-controlled international study. Lancet 2000;356:2031-2036.

34 Fujishiro H, Ferman TJ, Boeve BF, Smith GE, Graff-Radford NR, Uitti RJ, Wszolek ZK, Knopman DS, Petersen RC, Parisi JE, Dickson DW: Validation of the neuropathologic criteria of the third consortium for dementia with Lewy bodies for prospectively diagnosed cases. J Neuropathol Exp Neurol 2008;67:649-656.

35 Honda K, Hashimoto M, Yatabe Y, Kaneda K, Yuki S, Ogawa Y, Matsuzaki S, Tsuyuguchi A, Tanaka H, Kashiwagi H, Hasegawa N, Ishikawa T, Ikeda M: The usefulness of monitoring sleep talking for the diagnosis of Dementia with Lewy bodies. Int Psychogeriatr 2013;25:851-858.

36 Rockwell E, Choure J, Galasko D, Olichney J, Jeste DV: Psychopathology at initial diagnosis in dementia with Lewy bodies versus Alzheimer disease: comparison of matched groups with autopsy-confirmed diagnoses. Int J Geriatr Psychiatry 2000;15:819-823.

37 Srikanth S, Nagaraja AV, Ratnavalli E: Neuropsychiatric symptoms in dementia-frequency, relationship to dementia severity and comparison in Alzheimer's disease, vascular dementia and frontotemporal dementia. J Neurol Sci 2005;236:43-48.

38 Sadak TI, Katon J, Beck C, Cochrane BB, Borson S: Key neuropsychiatric symptoms in common dementias: prevalence and implications for caregivers, clinicians, and health systems. Res Gerontol Nurs 2014;7:44-52.

39 Boot BP, Orr CF, Ahlskog JE, Ferman TJ, Roberts R, Pankratz VS, Dickson DW, Parisi J, Aakre JA, Geda YE, Knopman DS, Petersen RC, Boeve BF: Risk factors for dementia with Lewy bodies: a case-control study. Neurology 2013;81:833-840. 